\section{Functional loss in early age-related maculopathy: the ischaemia postreceptoral hypothesis}

\begin{abstract}
We review proposed models and psychophysical and electrophysiological tests performed in many studies for early agerelated maculopathy (ARM). We suggest that ischaemia is the trigger for impaired retinal pigment epithelium function causing imbalance of secretion of vascular growth factors, reduced disc degradation capability and reduced metabolic activity and possible inflammatory response. This results in increased deposition of cell debris, such as drusen and thickens Bruch's membrane causing even more ischaemia of the overlying neurosensory retina. The photoreceptors are more resistant to ischaemia given their proximity to the choroid. Furthermore, being 'upstream' from the inner retinal layers, they act as an oxygen sink depriving retinal layers further from the choroid. Postreceptoral cell layers and especially parts of the inner nuclear layer that are located in the watershed zone between two sources of blood supply are preferentially vulnerable to ischaemia. Based on psychophysical and electrophysiological findings we propose that most of the function impairment in early ARM starts postreceptorally.

Eye (2007) 21, 689-696; doi:10.1038/sj.eye.6702389; published online 5 May 2006
\end{abstract}

Keywords: early age-related maculopathy; ARM; ischaemia; postreceptoral function; multifocal ERG; rod-mediated function

\section{Introduction}

Age-related maculopathy (ARM) has become a major public health issue in developed
B Feigl, B Brown, J Lovie-Kitchin and P Swann

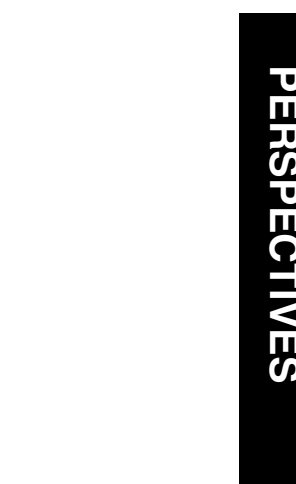

countries, as it is the leading cause of blindness in people aged over 65 years. ${ }^{1}$ The management and treatment of ARM remain an ongoing challenge. ${ }^{2-4}$ Its pathogenesis is still unclear and a genetic background together with environmental factors have been discussed. ${ }^{5-7}$ Photoreceptor death and vision loss result from subretinal choroidal neovascularization (CNV), from retinal pigment epithelium (RPE) detachment, or from central geographic atrophy in late ARM. These appear to occur in response to deposition of abnormal material within Bruch's membrane, which accumulate during the early course of ARM..$^{8-13}$ Current treatment options for ARM are limited, but they can be effective at slowing progression of the disease if applied early. ${ }^{14-18}$ It is important to investigate the early stage of ARM as defined by drusen and RPE abnormalities, ${ }^{19}$ where there is hardly any subjective vision function loss to better understand the pathogenesis and the mechanisms underlying ARM.

It is still not clear whether functional deficits in early ARM measured with various psychophysical tests are primarily caused by reduced sensitivity of photoreceptors, ${ }^{20-23}$ by postreceptoral damage $e^{21,24,25}$ or by damage to other tissues involved in ARM such as the RPE/Bruch's membrane complex ${ }^{10,11,26}$ or the choroid. ${ }^{27-31}$ Knowledge of the primary retinal site affected by ARM would be helpful in targeting the application of future treatments, such as pharmaceuticals, retinal transplants, or computer chips. Earlier detection and diagnosis of retinal changes would improve the efficient implementation of treatments and reduce the number of years individuals live with visual disability and subsequent costs to society, and perhaps lead to preventative treatments.
Institute of Health and Biomedical Innovation, School of Optometry, Queensland University of Technology, Brisbane, Queensland, Australia

Correspondence: B Feigl, Institute of Health and Biomedical Innovation, School of Optometry, Centre for Health and Biomedical Innovation, Queensland University of Technology,

Victoria Park Road, Kelvin Grove,

Queensland 4059, Australia Tel: +61 73864 5739;

Fax: + 61738645665 .

E-mail: b.feigl@qut.edu.au

Received: 29 November 2005

Accepted in revised form: 27 March 2006 Published online: 5 May 2006 
Psychophysical and electrophysiological function tests in ARM

An extensive overview of the subjective and objective cone- and rod-mediated function tests has been published recently. ${ }^{32,33}$ The functional results of these tests cannot be given in detail but all show an impairment of cone- or rod-mediated function (or both) in early ARM. In addition, there is preferential vulnerability of the S-cone ${ }^{34,35}$ and rod pathway ${ }^{36-42}$ in early ARM over the L- and M-cone pathway. $\mathrm{Curcio}^{43}$ has demonstrated that parafoveal rods were the first to die in early ARM and the last surviving photoreceptor in late ARM was a cone. Most studies have explained their functional findings as being due to an alteration at the photoreceptor level (abnormal orientation or shape or photoreceptor loss) and/or by the kinetic model. ${ }^{21,25,34,41,44,45}$ In contrast to a structural abnormality or loss of photoreceptors that might result in decreased photopigment and photosensitivity, the kinetic model suggests slowed regeneration of photopigment owing to slowed transfer of vitamin A to the retinoid cycle through a thickened Bruch's membrane. The kinetic model proposes that cones and rods have abnormal adaptation and therefore altered recovery dynamics caused by the dysfunction in the photopigment regenerative capacity. This hypothesis would suggest that the amount of abnormal deposits and thus drusen would correlate with poorer recovery dynamics. In fact, the contrary has been shown in a number of studies which report poor correlations between drusen and kinetic measures such as dark-adaptation or glare recovery. ${ }^{46-48}$ Elsner and Burns ${ }^{20}$ hypothesized that decreased photosensitivity did not imply primary damage to Bruch's membrane. They used colour match techniques and demonstrated that decreased photosensitivity of the cone photopigment was not correlated with slowed regeneration kinetics in early ARM. They suggested that the kinetic model does not explain all functional deficits in ARM and that there must be other factors possibly relating to microenvironmental alterations.

Another approach to explain the functional deficits might be related to perfusion abnormalities and ischaemia. Arterial hypertension, atherosclerosis, and hypercholesterinaemia that increase vascular rigidity and their effects on the ocular circulation and Bruch's membrane have been hypothesized to increase the risk for developing ARM. ${ }^{49}$ Vascular deficits have been identified in early and late ARM using fluorescein and indocyanine green angiography, laser Doppler flowmetry, and colour Doppler imaging. ${ }^{31,50}$ Pauleikhoff et $a l^{51}$ demonstrated that prolonged choroidal filling seen on fluorescein and indocyanine green angiography is a clinical marker for diffuse deposits in Bruch's membrane. Grunwald et $a l^{50}$ found that eyes with more advanced ARM fundus features such as drusen, RPE abnormalities, and CNV in the fellow eye tended to show more pronounced decrease in choroidal blood flow. Together with other authors ${ }^{52,53}$ they hypothesized that thickening of the RPE/Bruch's membrane complex would increase the distance that oxygen must travel from the choriocapillaris to the retina and that this would reduce the availability of oxygen and important metabolites to the outer retina. A haemodynamic model of ARM has been proposed by Friedman $e t a^{27}$ who hypothesized a progressive decrease in the compliance of the sclera and choroidal vessels, which is initiated by the deposition of lipid in the sclera and Bruch's membrane. This might result in a higher intravascular pressure with decreased ocular perfusion.

The perfusion abnormalities and the haemodynamic model together with the kinetic model suggest that the primary insult causing functional deficits in ARM is caused by lipid deposition within Bruch's membrane. However, we hypothesize a new mechanism in ARM that includes these previous models, but is driven by ischaemia and might explain most of the functional findings; we describe it in a new model (Figure 1a-e).

Ischaemia is defined as an imbalance between perfusion and demand for oxygenated blood. ${ }^{54}$ It is characterized not only by insufficiency of oxygen, but also reduced availability of nutrients and inadequate removal of metabolites. ${ }^{54}$ We propose that the primary insult causing functional deficits in early ARM is reduced ocular blood flow ${ }^{27,31}$ (Figure 1a) resulting in chronic ischaemia of the overlying tissues. ${ }^{50,52}$ Reduced ocular blood flow might cause imbalance of vascular growth factors such as vascular endothelial growth factor (VEGF) with diminution of VEGF from the RPE. An extensive review of growth factors involved in ARM has been given elsewhere. ${ }^{53,55}$ VEGFs have important roles in vascular permeability angiogenesis, and lymphangiogenesis and have neurotrophic and proinflammatory functions. ${ }^{55}$ VEGF depletion induces choroidal atrophy ${ }^{55-57}$ that might cause a further delay in perfusion. Impaired perfusion might also result in impaired function of the RPE with decreased degradation of photoreceptor disc membranes, reduced antioxidant capacity, and deposition of abnormal extracellular matrix ${ }^{58}$ and abnormal debris, the basal linear and basal laminar deposits ${ }^{59}$ possibly triggering an inflammatory response. ${ }^{60}$ Consequently, increased resistance of the choroid to blood flow by deposition of lipids in the sclera and in Bruch's membrane as hypothesized in the haemodynamic mode ${ }^{27}$ might occur (Figure 1b). The postulation of Bruch's membrane being 


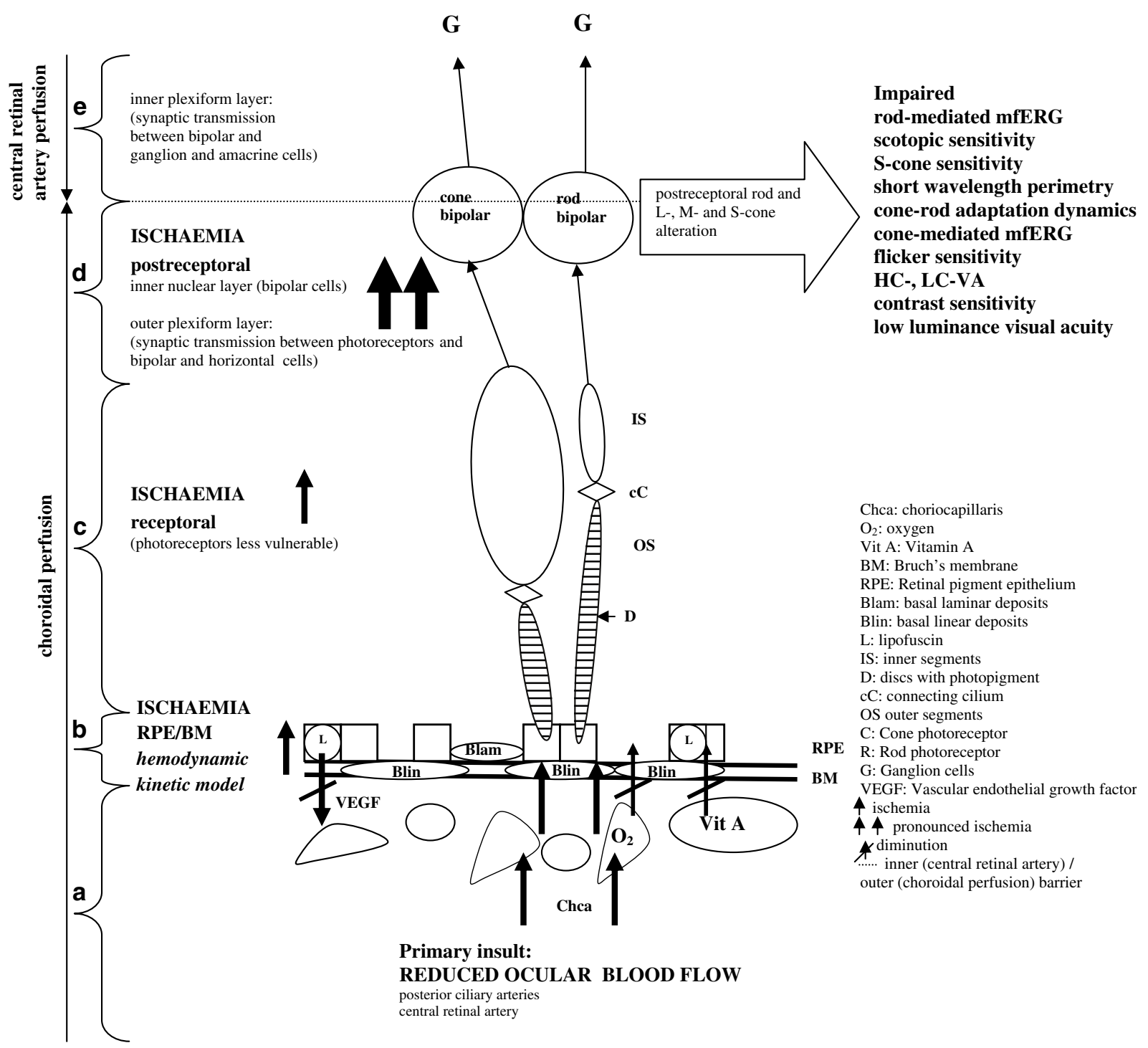

Figure 1 (a-e) Schematic representation of ischaemia postreceptoral model in early ARM.

a barrier has not only been demonstrated morphologically ${ }^{61,62}$ but also functionally in early ARM. ${ }^{63}$ A thickened Bruch's membrane ${ }^{61,62}$ may lead not only to reduced diffusion of oxygen ${ }^{50,53}$ and thus pronounced ischaemia distal to the membrane but also to an impaired transport capacity of important metabolites to the retinoid cycle (such as vitamin A, trans-retinol). Therefore, the photoreceptor circulation current is altered as synthesis of 11-cis retinal is slowed in the RPE as proposed in the kinetic model ${ }^{43}$ (Figure 1b). It is likely that the photoreceptors (Figure 1c) are more resistant to ischaemic insults than postreceptoral sites ${ }^{64-66}$ (Figure 1d) owing to their proximity to metabolic reserves available in the RPE and the choriocapillaris, ${ }^{66}$ and this is reflected in less functional alteration. The postreceptoral region is proposed to be particularly vulnerable to ischaemia as it is at the watershed zone between two sources of blood supply; the choroid and the central retinal artery (Figure 1e). It is likely that $\mathrm{L}-$ and $\mathrm{M}$-cone pathways are more resistant to hypoxia than S-cone and rod-pathways. ${ }^{67-71}$

\section{Discussion}

We suggest that in early ARM, the cone- and rodmediated postreceptoral pathways are primarily affected by chronic ischaemia, before the photoreceptors. Ischaemia might have an effect at the postreceptoral levels as photoreceptors and especially rods act as an oxygen $\sin \mathrm{k}^{66,71}$ and the postreceptor region is the watershed zone between two sources of blood supply (choroid and central retinal artery). 
Sarks et al (unpublished data) demonstrated that delayed choroidal perfusion on fluorescein angiography corresponded to focal loss and attenuation of the choroidal capillaries. In addition, regions of choroidal capillary dropout relate to diffuse deposits beneath the RPE histologically. ${ }^{72}$ Sarks and Sarks ${ }^{59}$ have shown (using electron microscopy) that the RPE cannot exist without the choriocapillaris, and when the RPE degenerates, the first retinal layers affected are the outer plexiform layers and the inner nuclear layer. ${ }^{73}$

The choroid supplies the overlying retina to a depth of $130 \mu \mathrm{m}$ including the outer parts the inner nuclear layer (and thus bipolar cells), ${ }^{74}$ is very susceptible to hypoxia and is thought to regulate oxygen tension poorly. ${ }^{75,76}$ It has been suggested that during hypoxia a compensatory increase in choroidal blood flow does not occur and a deficit on the choroidal site is not made up by increased supply from the retinal circulation. ${ }^{77} \mathrm{Yu}$ and Cringle ${ }^{65}$ and Cringle et $a l^{66}$ showed that there is a high rate of oxygen consumption in the outer and inner plexiform layers where there is high synaptic activity (Figure 1d, e) in animal models. A study involving the rat retina has indicated that there is higher oxygen uptake under light adapted conditions in the inner plexiform layer whereas dark adapted conditions increase oxygen consumption in the outer retina leaving the inner retina unaffected. ${ }^{66}$ Although there is reduced blood flow in the central retinal artery in $\mathrm{ARM}^{27}$ the inner retinal oxygen tension is better regulated during hypoxia ${ }^{76}$ with compensatory vasodilatation and increase in blood flow. ${ }^{78}$ This might be the reason why ganglion cells are better preserved in early ARM. ${ }^{79}$ However, in more advanced stages of ARM a loss can be also found (Figure 29, p. 571 in Sarks et $a l^{73}$ ).

Bui et $a l^{64}$ have investigated acute hypoxia with electrophysiological measures such as the full field electroretinogram (ERG) and found an immediate postischaemic postreceptoral b-wave loss, whereas photoreceptor responses were more gradually affected. They suggested that the acute selective postreceptoral loss was due to impaired glutamatergic neurotransmission or failure of glutamate recycling. ${ }^{64}$ It is known that acute ischaemia causes massive damage to the entire retina histopathologically. ${ }^{80}$ This is reflected in a postreceptoral-mediated b-wave amplitude loss and possibly amacrine cell-mediated reduction in oscillatory potentials electrophysiologically. ${ }^{80-83}$ Chronic (as opposed to acute) ischaemia is less likely to cause massive damage to retinal tissue and a delay in implicit times has been reported. ${ }^{64,80}$ For example in diabetes, a chronic ischaemic disease, delayed multifocal electroretinogram (mfERG) peak implicit times but no amplitude loss are seen; these findings predict the onset of diabetic retinopathy before ophthalmoscopically visible changes in subjects with diabetes. ${ }^{84}$ Sandberg et $a l^{85}$ found delayed implicit times in the focal ERG associated with prolonged choroidal perfusion in ARM eyes at risk, where the fellow eye had developed chorioretinal neovascularization. The authors suggested that delayed implicit times rather than amplitudes reflected chronic retinal ischaemia. ${ }^{85}$

A postreceptoral involvement of rod pathways as found in studies with the mfERG in early ARM ${ }^{38-40}$ is supported by Hood et $a l^{86}$ who compared the rodmediated mfERG with the full-field rod ERG. They suggested that the rod-mediated mfERG responses are like the full-field rod ERG with mainly bipolar cell responses and a very small photoreceptor contribution. ${ }^{86}$ The blue-yellow functional loss in early ARM might also reflect ischaemic conditions at postreceptoral levels. ${ }^{69}$ A selective early loss of S-cone postreceptoral pathways has been shown in other ischaemic diseases such as, for example, in diabetes with ${ }^{69,87}$ or without retinopathy. ${ }^{87,88}$ Additional evidence of primary postreceptoral involvement might be reflected by impaired high contrast-, low contrast-, low luminance (SKILL) visual acuity and contrast sensitivity as demonstrated in other studies in early ARM. ${ }^{21,89}$ Although these are mainly L- and M-photoreceptor properties, a loss of these functions is thought to relate to decreased efficiency in lateral inhibitory mechanisms that are mediated by horizontal and amacrine cells at the postreceptoral level (Figure 1d and e). ${ }^{90,91}$

Most recently Arden $e a^{71}$ have proposed a hypothesis based on a similar vicious cycle caused by ischaemia in ARM but mainly driven by the high oxygen consumption of the rods. The preferential vulnerability of rod pathways in ARM is supported by various psychophysical and electrophysiological studies. ${ }^{36,38,39,44,92}$ Arden et $\mathrm{al}^{71}$ suggested a primary defect in the RPE causes diminution of VEGF to the choriocapillaris which results in its atrophy. Also, Schlingemann ${ }^{53}$ suggested a disturbance of the paracrine relationship between the RPE and choriocapillaris. However, it is unclear which event occurs first, a primary defect at the RPE level ${ }^{53,71}$ or reduced ocular blood flow as suggested in our model. Nevertheless they all suggest an inevitable cycle driven by ischaemia. In the longer term chronic ischaemia that is caused by reduced oxygen supply to the choroid and reduced oxygen delivery to the retina might result in an upregulation of $\mathrm{VEGF}^{93}$ and well known consequences causing late ARM with chorioretinal neovascularization. ${ }^{94}$ Expression of some growth factors is stimulated by hypoxia, and their localization within choroidal neovascular membranes suggests that hypoxia may be an aetiologic factor for CNV. In studies of autopsy eyes, VEGF levels were found to be elevated in the RPE and choroidal blood vessels of maculae with age-related macular degeneration. ${ }^{95,96}$ 
Most recent and promising clinical trials with anti-VEGF aptamer $^{97}$ and anti-VEGF antibody ${ }^{98,99}$ show improvement of vision and therefore demonsterate that there is a strong link to ischaemia in ARM.

Recent work suggests that a chronic inflammatory response and complement factor $\mathrm{H}$ (a major regulator of the alternative complement pathway and defence system against inflammation) play important roles in the pathogenesis of ARM. ${ }^{7,100-102}$ It has been demonstrated that a polymorphism in the complement factor $\mathrm{H}$ gene makes a substantial contribution to ARM susceptibility. Cigarette smoke influences the plasma levels of factor $\mathrm{H}$ and has been shown to inhibit its activity. The relationship between smoking and ischaemic diseases ${ }^{103,104}$ and between smoking and $\mathrm{ARM}^{105}$ is well established. It could be hypothesized that chronic ischaemia in combination with genetic predisposition ${ }^{7,100,101,106}$ might trigger ARM and chronic inflammation.

We hypothesize that early function changes in ARM are initiated by chronic ischaemia of postreceptoral layers such as inner nuclear and possibly inner plexiform layers. This ischaemia affects primarily S-cone and rod-mediated postreceptoral pathways first owing to their lower resistance to ischaemia compared to L- and $\mathrm{M}$-cone pathways. Although cone- and rod-mediated impairment at photoreceptor level, as speculated from the psychophysical results found in other studies, $^{21,36,37,41,107,108}$ cannot be excluded, our model would suggest that this happens later in the course of the disease, possibly when ischaemia becomes prolonged and insufficient Vitamin $\mathrm{A}$ is provided through the thickened RPE/Bruch's membrane complex.

\section{Conclusion}

Early detection of impaired postreceptoral function before there is severe photoreceptor involvement and vision loss could lead to early commencement of treatment. However, whether an approach in the treatment of early ARM might include supplemental oxygen still needs to be investigated. There is some support for such an approach; improvement of diabetic cystoid oedema after oxygen therapy, as measured with the optical coherence tomography has recently been demonstrated. ${ }^{109}$ Use of supplemental oxygen as a treatment for ARM is not new ${ }^{110,111}$ but large clinical trials have never been initiated to show its possible beneficial effect.

\section{Acknowledgements}

We thank Dr Shirley Sarks, Dr Svetlana Cherepanoff and the Reviewers for their insightful and valuable comments on this manuscript. Beatrix Feigl was partially supported by the Dr Adele Rabensteiner-award of the Austrian Society of Ophthalmology.

\section{References}

1 Fine S. Age-related macular degeneration 1969-2004: a personal perspective. Am J Ophthalmol 2005; 139: 405-420.

2 Bird A. Age-related macular disease: an ongoing challenge. Clin Exp Ophthalmol 2003; 31: 461-463.

3 Bird A. Towards an understanding of age-related macular disease. Eye 2003; 17: 457-466.

4 Pauleikhoff D. Neovascular age-related macular degeneration. Natural history and treatment outcomes. Retina 2005; 25: 1062-1084.

5 International ABCR Screening Consortium. Statistically significant association of sequence variants in $\mathrm{ABCR}$ gene with age-related macular degeneration. AM J Hum Genet 2000; 67: 487-491.

6 Allikmets R, Shroyer N, Seddon J, Levis R, Bernstein P, Peiffer A et al. Mutation of the Stargardt disease gene (ABCR) in age-related macular degeneration. Science 1997; 277: 1805-1807.

7 Hageman G, Anderson D, Johnson L, Hancox L, Taiber A, Hardisty L et al. A common haplotype in the complement regulatory gene factor $\mathrm{H}(\mathrm{HF} 1 / \mathrm{CFH})$ predisposes individuals to age-related macular degeneration. Proc Natl Acad Sci USA 2005; 102: 7227-7232.

8 Gass J. Pathogenesis of disciform macular detachment of the neuro-epithelium. 3. Senile disciform macular degeneration. Am J Ophthalmol 1967; 63: 617-644.

9 Sarks J, Sarks S, Killingworth M. Evolution of soft drusen in age-related macular degeneration. Eye 1994; 8: 269-283.

10 Guymer R, Luthert P, Bird A. Changes in Bruch's membrane and related structures with age. Prog Ret Eye Res 1998; 18: 59-90.

11 Bird A. Pathogenesis of retinal pigment epithelial detachment in the elderly; the relevance of Bruch's membrane change. Eye 1991; 5: 1-12.

12 Boulton M, Dayhaw-Barker P. The role of the retinal pigment epithelium: topographical variations and ageing changes. Eye 2001; 15: 384-389.

13 Holz F, Pauleikhoff D, Klein R, Bird A. Pathogenesis of lesions in late age-related macular disease. $A m \mathrm{~J}$ Ophthalmol 2004; 137: 504-510.

14 Bressler N, Treatment of Age-Related Macular Degeneration With Photodynamic Therapy (TAP) Study Group. Photodynamic therapy of subfoveal choroidal neovascularization in age-related macular degeneration with verteporfin: two-year results of 2 randomized clinical trials-tap report 2. Arch Ophthalmol 2001; 119: 198-207.

15 Treatment of Age-Related Macular Degeneration With Photodynamic Therapy (TAP) Study Group. Verteporfin therapy for subfoveal choroidal neovascularisation in age-related macular degeneration: three-year results of an open-label extension of 2 randomized clinical trials - TAP report no. 5. Arch Ophthalmol 2002; 120: 1307-1314.

16 Macular Photocoagulation Study Group. Laser photocoagulation of subfoveal neovascular lesions in age-related macular degeneration. Updated findings from two clinical trials. Arch Ophthalmol 1993; 111: 1200-1209.

17 Age- Related Eye Disease Study Research Group. A randomized, placebo-controlled, clinical trial of high dose 
supplementation with vitamins $\mathrm{C}$ and $\mathrm{E}$, betacarotene and zinc for age-related macular degeneration and vision loss - AREDS report no 8. Arch Ophthalmol 2001; 119: 1417-1436.

18 Gragoudas E, Adamis A, Cunningham E, Feinsod M, Guyer D, for the VEGF Inhibition Study in Ocular Neovascularisation Clinical Trial Group. Pegaptanib for neovascular age-related macular degeneration. $N$ Engl J Med 2004; 351: 2805-2816.

19 Bird A, Bressler N, Bressler S, Chisholm I, Coscas G, Davis $\mathrm{M}$ et al. An international classification and grading system for age-related maculopathy and age-related macular degeneration. The International ARM Epidemiological Study Group. Surv Ophthalmol 1995; 39: 367-374.

20 Elsner A, Burns S. Cone photopigment in older subjects: decreased optical density in early age-related macular degeneration. J Opt Soc Am A 2002; 19: 215-222.

21 Phipps J, Guymer R, Vingrys A. Loss of cone function in age-related maculopathy. Invest Ophthalmol Vis Sci 2003; 44: 2277-2283.

22 Smith V, Pokorny J, Diddie K. Color matching and Stiles-Crawford effect in observers with early age-related macular degeneration. J Opt Soc Am A 1988; 5: 2113-2121.

23 Zele AJ, O'Loughlin RK, Guymer RH, Vingrys AJ. Disclosing disease mechanism with a spatio-temporal summation paradigm. Graefe's Arch Clin Exp Ophthalmol 2006; 244: 425-432.

24 Mayer M, Spiegler S, Ward B, Glucs A, Kim C. Mid-frequency loss of foveal flicker sensitivity in early stages of age-related maculopathy. Invest Ophthalmol Vis Sci 1992; 33: 3136-3142.

25 Phipps JA, Dang TM, Vingrys AJ, Guymer RH. Flicker perimetry losses in age-related macular degeneration. Invest Ophthalmol Vis Sci 2004; 45: 3355-3360.

26 Pauleikhoff D. Drusen in Bruch's membrane. Their significance for the pathogenesis and therapy of age-associated macular degeneration. Ophthalmology 1992; 89: 363-386.

27 Friedman E, Krupsky S, Lane A, Oak S, Friedman E, Egan $\mathrm{K}$ et al. Ocular blood flow velocity in age-related macular degeneration. Ophthalmology 1995; 102: 640-646.

28 Chen J, Fitzke F, Pauleikhoff D, Bird A. Functional loss in age-related Bruch's membrane change with choroidal perfusion defect. Invest Ophthalmol Vis Sci 1992; 33: 334-340.

29 Grunwald J, Hariprasad S, DuPont J, Maguire M, Fine S, Brucker A et al. Foveal choroidal blood flow in age-related macular degeneration (AMD). Invest Ophthalmol Vis Sci 1998; 39: 385-390.

30 Pauleikhoff D, Chen J, Chisholm I, Bird A. Choroidal perfusion abnormality with age-related Bruch's membrane change. Am J Ophthalmol 1990; 109: 211-217.

31 Ciulla T, Harris A, Chung H. Color Doppler imaging discloses reduced ocular blood flow velocities in non-exudative age-related macular degeneration. Am J Ophthalmol 1999; 128: 75-80.

32 Lovie-Kitchin J, Feigl B. Assessment of age-related maculopathy using subjective vision tests. Clin Exp Optom 2005; 88: 292-303.

33 Feigl B, Lovie-Kitchin J, Brown B. Objective functional assessment of age-related maculopathy: a special application for the multifocal electroretinogram. Clin Exp Optom 2005; 88: 304-312.
34 Eisner A, Klein M, Zilis J, Watkins M. Visual function and the subsequent development of exudative age-related macular degeneration. Invest Ophthalmol Vis Sci 1992; 33: 3091-3102.

35 Collins M. Pre-age-related maculopathy and the desaturated D-15 colour vision test. Clin Exp Opt 1986; 69: 223-227.

36 Owsley C, Jackson G, White M, Edwards D. Delays in rod-mediated dark-adaptation in early age-related maculopathy. Ophthalmology 2001; 108: 1196-1202.

37 Owsley C, Jackson G, Cideciyan A, Huang Y, Fine S, Ho A et al. Psychophysical evidence for rod vulnerability in age-related macular degeneration. Invest Ophthalmol Vis Sci 2000; 41: 267-273.

38 Feigl B, Brown B, Lovie-Kitchin J, Swann P. Cone- and rod-mediated $\mathrm{mfERG}$ in early age-related maculopathy. Eye 2005; 19: 431-441.

39 Feigl B, Brown B, Lovie-Kitchin J, Swann P. Monitoring retinal function in early age-related maculopathy: visual performance after one year. Eye 2005; 19: 1169-1177.

40 Chen C, Wu L, Wu D, Huang S, Wen F, Luo G et al. The local cone and rod system function in early age-related macular degeneration. Doc Ophthalmol 2004; 109: 1-8.

41 Steinmetz R, Haimovici R, Jubb C, Fitzke F, Bird A. Symptomatic abnormalities of dark adaptation in patients with age-related Bruch's membrane change. $\mathrm{Br} \mathrm{J}$ Ophthalmol 1993; 77: 549-554.

42 Scholl H, Bellmann C, Dandekar S, Bird A, Fitzke F. Photopic and scotopic fine matrix mapping of retinal areas of increased fundus autofluorescence in patients with age-related maculopathy. Invest Ophthalmol Vis Sci 2004; 45: 574-583.

43 Curcio C. Photoreceptor topography in aging and age-related maculopathy. Eye 2001; 15: 376-383.

44 Jackson GR, Owsley C, Curcio CA. Photoreceptor degeneration and dysfunction in aging and age-related maculopathy. Ageing Res Rev 2002; 1: 381-396.

45 Curcio C, Owsley C, Jackson G. Spare the rods, save the cones in aging and age-related maculopathy. Invest Ophthalmol Vis Sci 2000; 41: 2015-2018.

46 Collins M, Brown B. Glare recovery and its relation to other clinical findings in age related maculopathy. Clin Vis Sci 1989; 4: 155-163.

47 Cheng A, Vingrys A. Visual losses in early age-related maculopathy. Optom Vis Sci 1993; 70: 89-96.

48 Eisner A, Stoumbos V, Klein M, Fleming A. Relation between fundus appearance and function. Eyes whose fellow eye has exudative age-related macular degeneration. Invest Ophthalmol Vis Sci 1991; 32: 8-20.

49 Vingerling J, Dielemans I, Bots M, Hofman A, Grobbee D, de Jong P. Age-related macular degeneration is associated with atherosclerosis. The Rotterdam Study. Am J Epidemiol 1995; 142: 404-409.

50 Grunwald J, Metelitsina T, DuPont J, Ying G-S, Maguire M. Reduced foveolar choroidal blood flow in eyes with increasing AMD severity. Invest Ophthalmol Vis Sci 2005; 46: 1033-1038.

51 Pauleikhoff D, Spital G, Radermacher M, Brumm G, Lommatzsch A, Bird A. A fluorescein and indocyanine green angiographic study of choriocapillaris in age-related macular disease. Arch Ophthalmol 1999; 117: 1353-1358. 
52 Linsenmeier R, Padnick-Silver L. Metabolic dependence of photoreceptors on the choroid in the normal and detached retina. Invest Ophthalmol Vis Sci 2000; 41: 3117-3123.

53 Schlingemann R. Role of growth factors and the wound healing response in age-related macular degeneration. Graefe's Arch Clin Exp Ophthalmol 2004; 242: 91-101.

54 Robbins S, Cotran R. Robbins and Cotran pathologic basis of disease. In: Kumar V, Abbas AK, Fausto N (eds). Robbins and Cotran Pathologic Basis of Disease, 7th ed. Saunders: Philadelphia, 2004.

55 Witmer A, Vrensen G, Van Noorden C, Schlingemann R. Vascular endothelial growth factors and angiogenesis in eye disease. Prog Ret Eye Res 2003; 22: 1-29.

56 Sakamoto T, Sakamoto H, Murphy T, Spee C, Soriano D, Ishibashi $\mathrm{T}$ et al. Vessel formation by choroidal endothelial cells in vitro is modulated by retinal pigment epithelium cells. Arch Ophthalmol 1995; 113: 512-520.

57 Ramrattan R, van der Schaft T, Mooy C, de Bruijin W, Mulder P, de Jong P. Morphometric analysis of Bruch's membrane, the choriocapillaris, and the choroid in aging. Invest Ophthalmol Vis Sci 1994; 35: 2857-2864.

58 Zarbin M. Current concepts in the pathogenesis of age-related macular degeneration. Arch Ophthalmol 2004; 122: 598-641.

59 Sarks S, Sarks J. Age-related maculopathy: nonneovascular age-related macular degeneration and the evolution of geographic atrophy. In: Ryan SJ, Schachat AP (eds). Retina. 3rd edn. Medical Retina,vol.2 Mosby: Philadelphia, 2001, pp 1064-1099.

60 Hageman G, Luthert P, Victor Chong N, Johnson L, Anderson D, Mullins R. An integrated hypothesis that considers drusen as biomarkers of immune-mediated processes at the RPE-Bruch's membrane interface in aging and age-related macular degeneration. Prog Retinal Eye Res 2001; 20: 705-732.

61 Pauleikhoff D, Harper C, Marshall J, Bird A. Ageing changes in Bruch's membrane. A histochemical and morphological study. Ophthalmology 1990; 97: 171-178.

62 Holz F, Sheraidah G, Pauleikhoff D, AC B. Analysis of lipid deposits extracted from human macular and peripheral Bruch's membrane. Arch Ophthalmol 1994; 112: 402-406.

63 Arden G, Wolf J. Differential effects of light and alcohol on the electro-oculographic responses of patients with age-related macular disease. Invest Ophthalmol Vis Sci 2003; 44: 3226-3232.

64 Bui BV, Vingrys AJ, Kalloniatis M. Correlating retinal function and amino acid immunocytochemistry following post-mortem ischemia. Exp Eye Res 2003; 77: 125-136.

65 Yu D-Y, Cringle S. Oxygen distribution and consumption within the retina in vascularised and avascular retinas and in animal models of retinal disease. Prog Ret Eye Res 2001; 20: $175-208$.

66 Cringle S, Yu D-Y, Yu P, Su E-N. Intraretinal oxygen consumption in the rat in vivo. Invest Ophthalmol Vis Sci 2002; 43: 1922-1927.

67 Smith VC, Ernest T, Pokorny J. Effect of hypoxia on FM 100-hue test performance. Mod Probl Ophthalmol 1976; 17: 248-256.

68 Arden G, Wolf J, Tsang Y. Does dark adaptation exacerbate diabetic retinopathy? Evidence and a linking hypothesis. Vision Res 1997; 38: 1723-1729.

69 Greenstein V, Hood D, Ritch R, Steinberg R, Carr RS. Blue) cone pathway vulnerability in retinitis pigmentosa, diabetes and glaucoma. Invest Ophthalmol Vis Sci 1989; 30: 1732-1737.

70 Greenstein V, Hood D, Carr R. S cone pathway vulnerability: differential effects of retinitis pigmentosa and diabetes. Invest Ophthalmol Vis Sci 1987; 28: 113.

71 Arden G, Sidman R, Arap W, Schlingemann R. Spare the rod and spoil the eye. Br J Ophthalmol 2005; 89: 764-769.

72 McLeod DS, Lutty GA. High-resolution histologic analysis of the human choroidal vasculature. Invest Ophthalmol Vis Sci 1994; 35: 3799-3811.

73 Sarks J, Sarks S, Killingworth M. Evolution of geographic atrophy of the retinal pigment epithelium. Eye 1988; 2: 552-577.

74 Hayreh S, Gartner S. In vivo choroidal circulation and its watershed zones. Eye 1990; 4: 273-289.

75 Linsenmeier R. Electrophysiological consequences of retinal hypoxia. Graefe's Arch Clin Exp Ophthalmol 1990; 228: 143-150.

76 Linsenmeier R, Braun R. Oxygen distribution and consumption in the cat retina during normoxia and hypoxia. J Gen Physiol 1992; 99: 177-197.

77 Friedman E, Chandra S. Choroidal blood flow. III Effects of oxygen and carbon dioxide. Arch Ophthalmol 1972; 87: 70-71.

78 Eperon G, Johnson M, David N. The effect of arterial $\mathrm{PO}_{2}$ on relative retinal blood flow in monkeys. Invest Ophthalmol Vis Sci 1975; 14: 342-352.

79 Medeiros N, Curcio A. Preservation of ganglion cell layer neurons in age-related macular degeneration. Invest Ophthalmol Vis Sci 2001; 42: 795-803.

80 Grozdanic S, Sakaguchi D, Kwon Y, Kardon R, Sonea I. Functional characterization of retina and optic nerve after acute ocular ischemia in rats. Invest Ophthalmol Vis Sci 2003; 44: 2597-2605.

81 Johnson A, Lutty G, McLeod D, Otsuji T, Flower R, Sandagar $\mathrm{G}$ et al. Ocular structure and function in an aged monkey with spontaneous diabetes mellitus. Exp Eye Res 2005; 80: 37-42.

82 Coleman K, Fitzgerald D, Eustace P, Bouchier-Hayes D. Electroretinography, retinal ischemia and carotid artery disease. Eur J Vasc Surg 1990; 4: 13-18.

83 Block F, Schwarz M. The b-wave of the electroretinogram as an index of retinal ischemia. Gen Pharmacol 1998; 30: 281-287.

84 Han Y, Bearse MJ, Schneck M, Barez S, Jacobson C, Adams A. Multifocal electroretinogram delays predict sites of subsequent diabetic retinopathy. Invest Ophthalmol Vis Sci 2004; 45: 948-954.

85 Sandberg M, Miller S, Gaudio A. Foveal cone ERGs in fellow eyes of patients with unilateral neovascular age-related macular degeneration. Invest Ophthalmol Vis Sci 1993; 34: 3477-3480.

86 Hood D, Wladis E, Shady S, Holopigian K, Li J, Seiple W. Multifocal rod electroretinograms. Invest Ophthalmol Vis Sci 1998; 39: 1152-1161.

87 Han Y, Adams A, Bearse M, Schneck M. Multifocal electroretinogram and short-wavelength automated perimetry measures in diabetic eyes with little or no retinopathy. Arch Ophthalmol 2004; 122: 1809-1815.

88 Schneck M, Fortune B, Switkes E, Crognale M, Adams A. Acute effects of blood glucose on chromatic visually evoked potentials in persons with diabetes and in normal persons. Invest Ophthalmol Vis Sci 1997; 38: 800-810. 
89 Feigl B, Brown B, Lovie-Kitchin J, Swann P. Cone-mediated multifocal electroretinogram in early age-related maculopathy and its relationships with subjective macular function tests. Curr Eye Res 2004; 29: 327-336.

90 Brown B, Garner L. Effects of luminance on contrast sensitivity in senile macular degeneration. Am J Optom Physiol Opt 1983; 60: 788-793.

91 Brown B, Lovie-Kitchin J. Contrast sensitivity in central and paracentral retina in age-related maculopathy. Clin Exp Opt 1987; 70: 145-148.

92 Chen C, Wu L, Jiang F, Liang J, Wu D. Scotopic sensitivity of central retina in early age-related macular degeneration. Yan Ke Хue Bao 2003; 19: 15-19.

93 Blaauweegers H, Holtkamp G, Rutten H, Witmer AN, Koolwijk P, Patanen A et al. Polarized vascular endothelial growth factor secretion by human retinal pigment epithelium and localisation of vascular endothelial growth factor receptors on the inner choriocapillaris. Evidence for a paracrine relation. Am J Pathol 1999; 155: 412-428.

94 Lip P, Blann A, Hope-Ross M, Gibson J, Lip G. Age-related macular degeneration is associated with increased vascular growth factor, hemorheology and endothelial dysfunction. Ophthalmology 2001; 108: 705-710.

95 Kliffen M, Sharma H, Mooy C, Kerkvliet S, de Jong P. Increased expression of angiogenic growth factors in age-related maculopathy. Br J Ophthalmol 1997; 81: 154-162.

96 Amin R, Puklin J, Frank R. Growth factor localisation in choroidal neovascular membranes of age-related macular degeneration. Invest Ophthalmol Vis Sci 1994; 35: 3178-3188.

97 Gonzales C, VEGF Inhibition Study In Ocular Neovascularisation (V.I.S.I.O.N) Clinical Trial Group. Enhanced efficacy associated with early treatment of neovascular age-related macular degeneration with pegaptanib sodium: an exploratory analysis. Retina 2005; 25: $815-827$.

98 Avery R, Pieramici D, Rabena M, Castellarin A, Nasir M, Guist M. Intravitreal bevacizumab (Avastin) for neovascular age-related macular degeneration. Ophthalmology 2006; 113: 363-372.

99 Heier J, AN A, Pavan P, Leff S, Rosenfeld P, Ciulla T et al. Ranibizumab for treatment of neovascular age-related macular degeneration a phase I/II multicenter, controlled, multidose study. Ophthalmology 2006; 2006 February 13 [E-pub ahead of print].

100 Klein R, Zeiss C, Chew E, Tsai J-Y, Sackler R, Haynes C et al. Complement factor $\mathrm{H}$ polymorphism in age-related macular degeneration. Science 2005; 308: 385-389.

101 Zareparsi S, Branham K, Li M, Shah S, Klein R, Ott J et al. Strong association of the $\mathrm{Y} 402 \mathrm{H}$ variant in complement factor $\mathrm{H}$ at $1 \mathrm{q} 32$ with susceptibility to age-related macular degeneration. Am J Hum Genet 2005; 77: 149-153.

102 Bok D. Evidence for an inflammatory process in age-related macular degeneration gains new support. Proc Natl Acad Sci 2005; 102: 7053-7054.

103 Ezzati M, Henley S, Thun M, Lopez A. Role of smoking in global and regional cardiovascular mortality. Circulation 2005; 112: 489-497.

104 Hankey G. Preventable stroke and stroke prevention. J Thromb Haemost 2005; 3: 1638-1645.

105 Mitchell P, Wang J, Smith W, Leeder S. Smoking and the 5-years incidence of age-related maculopathy: The Blue Mountain Eye Study. Arch Ophthalmol 2002; 120: 1357-1363.

106 Haines J, Schnetz-Boutaud N, Schmidt S, Scott W, Agarwal $\mathrm{A}$, Postel E et al. Functional candidate genes in age-related macular degeneration: significant association with VEGF, VLDLR, andLRP6. Invest Ophthalmol Vis Sci 2006; 47: 329-335.

107 Jackson G, Owsley C, Curcio C. Photoreceptor degeneration and dysfunction in aging and age-related maculopathy. Ageing Res Rev 2002; 1: 381-396.

108 Haimovici R, Owens S, Fitzke F, Bird A. Dark adaptation in age-related macular degeneration: relationship to the fellow eye. Graefe's Arch Clin Exp Ophthalmol 2002; 240: 90-95.

109 Nguyen Q, Shah S, Van Anden E, Sung J, Vitale S, Campochiaro P. Supplemental oxygen improves diabetic macular edema: a pilot study. Invest Ophthalmol Vis Sci 2004; 45: 617-624.

110 Riva Sanseverino E, Meduri R, Pizzino A, Prantera M, Martini E. Effects of oxygen-ozone therapy on age-related degenerative retinal maculopathy. Panminerva Med 1990; 32: 77-84.

111 Teichmann K. Treatment of macular degeneration, according to Bangerter. Eur Med Res 1997; 2: 445-454. 